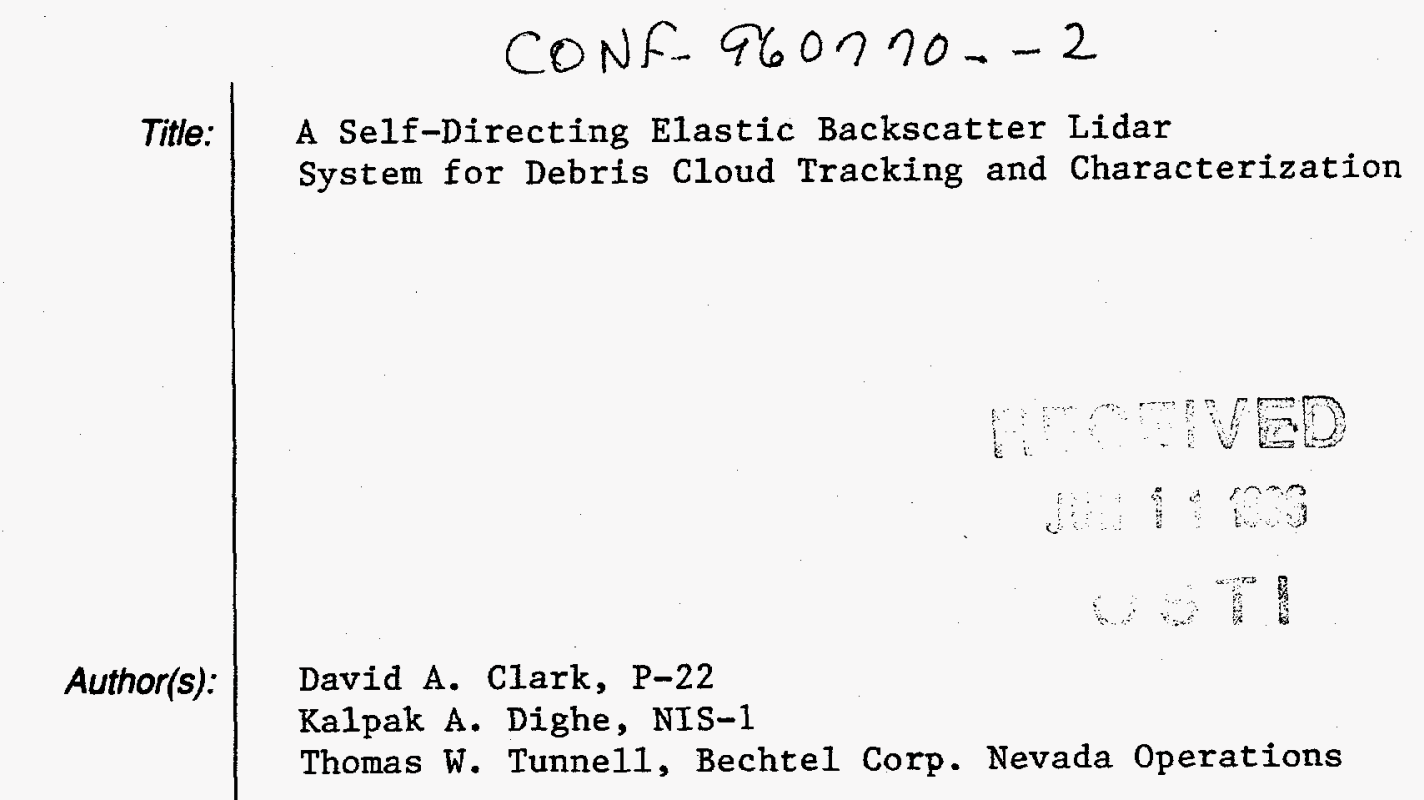

Submitted to:

The 18th International Laser Radar Conference Berlin, 22-26 July, 1996

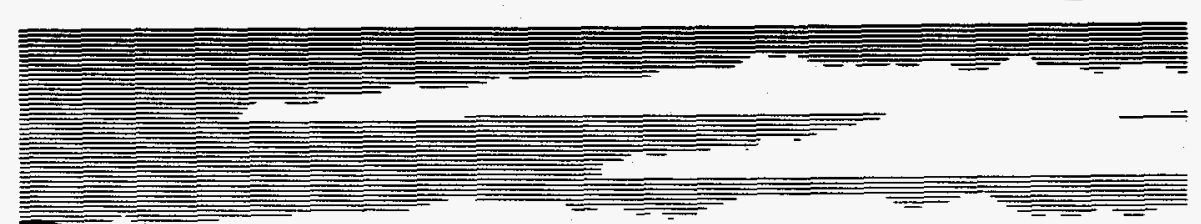

Los Alamos National Laboratory, an affirmative actionequal opportunity emplöyer, is operated by the University of California for the U.S. Department of Energy under contract W-7405-ENG-36. By acceptance of this article, the publisher recognizes that the U.S. Government retains a nonexclusive, royalty-free license to publish or reproduce the published form of this contribution, or to allow others to do so, for U.S. Government purposes. The Los Alamos National Laboratory requests that the publisher identily this article as work performed under the auspices of the U.S. Department of Energy. 


\section{DISCLAIMER}

This report was prepared as an account of work sponsored by an agency of the United States Government. Neither the United States Government nor any agency thereof, nor any of their employees, makes any warranty, express or implied, or assumes any legal liability or responsibility for the accuracy, completeness, or usefulness of any information, apparatus, product, or process disclosed, or represents that its use would not infringe privately owned rights. Reference herein to any specific commercial product, process, or service by trade name, trademark, manufacturer, or otherwise does not necessarily constitute or imply its endorsement, recommendation, or favoring by the United States Government or any agency thereof. The views and opinions of authors expressed herein do not necessarily state or reflect those of the United States Government or any agency thereof. 


\section{DISCLAIMER}

Portions of this document may be illegible in electronic image products. Images are produced from the best available original document. 


\title{
A Self-Directing Elastic Backscatter Lidar System for Debris Cloud Tracking and Characterization
}

\author{
David A. Clark ${ }^{1}$, Kalpak A. Dighe ${ }^{1}$ and Thomas W. Tunnell ${ }^{2}$ \\ ${ }^{1}$ Los Alamos National Laboratory, Los Alamos, NM 87545, USA \\ E-mail: daclark@lanl.gov, kdighe@lanl.gov \\ ${ }^{2}$ Bechtel Nevada, Los Alamos Operations, Los Alamos, NM 87545, USA \\ E-mail: tunnell-tw@egg.nv.doe.gov
}

\begin{abstract}
An elastic backscatter lidar that utilizes the lidar signal itself to direct the system towards fast moving isolated aerosol clouds has been developed. System capabilities include tracking clouds as well as measuring their volume and density distribution. Results of the first system tests are given.
\end{abstract}

\section{Introduction}

The advent of lidar (laser radar) has facilitated the study of atmospheric composition and dynamics. Lidar has been employed in monitoring the continuous flow of effluent gases and aerosols emanating from industrial stacks. However, detecting and tracking invisible transient effuents from unknown locations, though conceptually straightforward, has still remained experimentally challenging. We present here the first results from a newly designed elastic backscatter lidar system that is capable of detecting and tracking transient visible or subvisible aerosol plumes. Accurate cloud volume, cloud density distribution, and track information have been obtained on small, fast moving, subvisible debris clouds resulting from above ground tests in which conventional explosives were detonated.

Measurement of respirable fractions (fraction of specific materials released to the atmosphere as particulate matter having diameters less than 10 microns) has been challenging in the past. Early experiments that employed photographic techniques [1] and ground-based particle sampling systems to measure cloud volume and constituents were subject to obvious drawbacks. The cloud volume measurements would be crude due to difficulty in measuring all the cloud convolutions, and the triangulation advantage diminished as the clouds moved away from the cameras. Clearly, volume measurements were impossible for invisible clouds. Furthermore, the clouds often missed the effective range of ground-based particle sensors.

To overcome these and other difficulties, a new lidar control system that utilizes the backscatter signal itself to direct the lidar toward the cloud, while minimizing the scan dimensions, was developed. We anticipate integrating this lidar system with air sampling instrumentation mounted to a remotely piloted vehicle (RPV) [2] that is directed by the lidar. Data from the RPV will be combined with lidar information to yield comprehensive cloud analyses. 


\section{System Description}

Automatic cloud tracking software was added to an existing elastic lidar system having the following characteristics: Laser: Nd:YAG, $1064 \mathrm{~nm}$ wavelength, $50 \mathrm{~Hz}$, $500 \mathrm{~mJ} /$ pulse maximum; Telescope: $42 \mathrm{~cm}$ diameter $\mathrm{f} / 8$ Cassegrain; Detector: $3 \mathrm{~mm}$ diameter silicon avalanche photodiode; Computer: $486 / \mathrm{DX}, 60 \mathrm{MHz} \mathrm{PC}$; Digitizer: LeCroy 8818 , 8-bit, 8 kbyte memory, $100 \mathrm{MHz}$ maximum sample rate.

System operation is conceptually simple. In anticipation of the sudden appearance of a debris cloud, the lidar is set to a raster scan mode that covers a large volume of space over the expected release location. Low resolution (large angular step) scans are made repeatedly over the same volume. Digitized data from each laser shot are processed to look for a signal that is statistically significant when compared to signal from ambient aerosols. Data are not stored while ambient signals only are present. When signals above ambient are detected, their positions are used to resize the scan volume (window) to cover the area of interest. Considering existing wind conditions and expected lofting rate, parameters that are entered by the operator before operation begins, the window is automatically sized to encompass the region of interest and allow room for cloud motion. After the new window is set, another raster scan is taken. Then, again, the locations of significant signals are used to resize the scan window, data are stored, and another scan begins. These self-perpetuating sequences are repeated until the cloud either moves out of range, out of the preset, fixed, safety envelope, or operation is terminated by the operator. Thus, operation of the system is completely autonomous from the time the operator starts scanning the original large volume.

Real time calculations are done to direct the lidar, but, at present, detailed data analysis is performed offline. In post-processing, data points are identified either as "cloud data" or "not-cloud data". The logic is very similar to that used for signal extraction during data acquisition but is more sophisticated in order to extract weaker cloud signals. Cloud edges are carefully determined with a signal processing technique that compares each point with its nearest neighbors. Cloud volume is then computed. Analysis shows that the expected error in volume is 5 percent or less $[3,4]$. Also, cloud density is calculated and expressed relative to the scattering strength of ambient aerosols.

\section{Experiments}

For the two experiments described herein, the lidar system was set up on a hillside overlooking the sites where explosives were to be tested. The terrain was characterized by deep canyons and evergreen forests on mesa tops. One site was at a distance of about $6.5 \mathrm{~km}$ and the other was at about $5 \mathrm{~km}$. Neither of the test sites could be seen from the lidar as they were obscured by trees and slopes. A level line of sight from the lidar was one to two hundred meters above the explosions.

The first experiment was conducted at the $6.5 \mathrm{~km}$ distant site on a sunny afternoon day. About $1 \mathrm{~kg}$ of high explosives was detonated. The resulting explosion was so feeble and so distant that it was neither audible nor visible to 
the lidar operators. However, after the debris cloud had lofted into the lidar field of view, the system automatically locked onto the invisible cloud and proceeded to acquire data. Figure 1 shows scan windows 1 and 8 . One can see that the cloud is entirely encompassed within each scan. For clarity, the intermediate six scan windows are not shown. Cloud volumes ranged from $0.394 \mathrm{x}$ $10^{6} \mathrm{~m}^{3}$ to $2.83 \times 10^{6} \mathrm{~m}^{3}$.

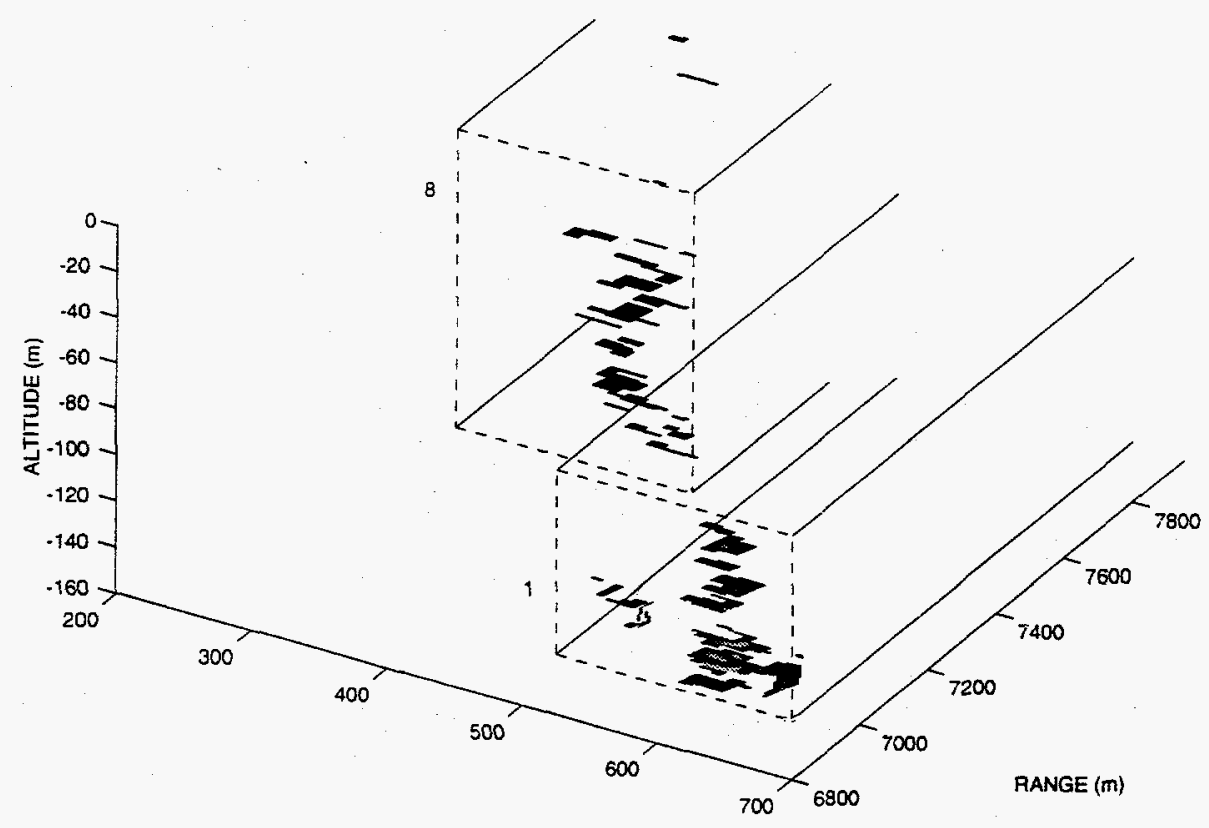

TRANSVERSE DISTANCE (m)

Fig. 1. The outlined boxes define the dimensions of scan windows 1 and 8 as set by the lidar control mechanism. Time between the scans is approximately three minutes.

The second experiment had a larger charge of explosives and was detonated after dark at the site $5 \mathrm{~km}$ away. A flash was seen by the lidar operators but the debris cloud was not visible. Figures 2 (a) and (b) are cross-sectional views depicting the density of the cloud during its evolution.

\section{Summary and Future Development}

An automatic cloud tracking and mapping elastic lidar has been developed and tested. Two experiments were performed in which the system successfully tracked and obtained data on invisible clouds. Applications of a cloud tracking lidar system are numerous, from environmental monitoring to defensive military applications such as detection of chemical aerosols and biological warfare agents.

For upcoming series of experiments, we anticipate having a more intelligent tracking control system. The lidar cloud track information will direct a RPV 
through invisible clouds. Incidentally, volumetric wind field measurements can be acquired with the same lidar system [5] before and after the experiments to provide input to the system.

The next major scientific upgrade to the present system shall be the addition of adaptive processing capabilities to achieve real-time 3D visualization of transient clouds. To this end, efforts are currently underway to implement adaptive algorithms, including neural networks, on massively parallel machines to characterize the backscattered signal.

In the future, this cloud tracking lidar can direct other remote sensing devices, such as DIAL or Raman lidar, for species identification. Such devices, which often require long integration times, would then be free to interrogate a specific part, eg. the centroid, of the cloud without having to scan the cloud or its surroundings.

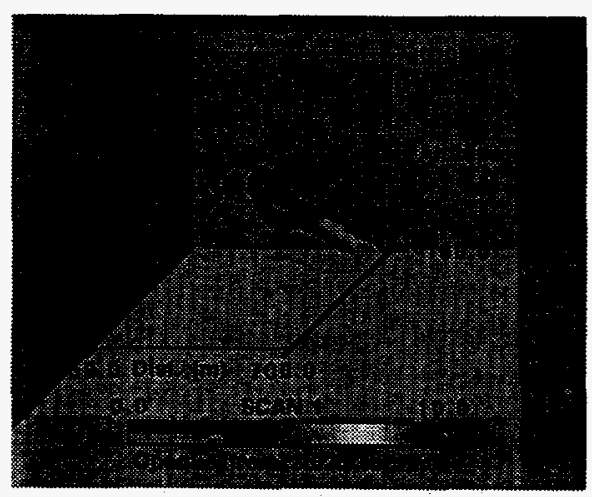

(a)

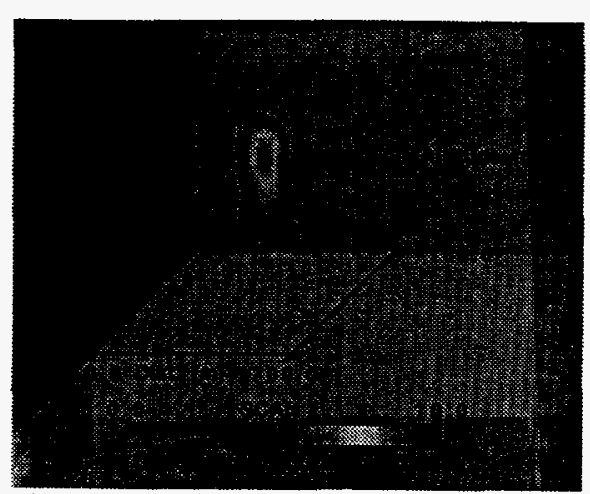

(b)

Fig. 2. (a) and (b) represent temporal cross-sectional views of the plume resulting from the second detonation. Note the decreasing density as the cloud disperses.

\section{References}

1. Dahl, D. A. and Johnson, L. J.: Los Alamos National Laboratory Report LA-UR-77-681. (1977)

2. Stephens, J. R.: Monitoring of atmospheric aerosol emissions using a RPV-borne sensor suite, to be presented at the Second International Airborne Remote Sensing Conference and Exhibition, 24-27 June 1996, San Fransisco, CA, USA

3. Tunnell, T. W. and Clark, D. A.: Debris cloud characterization with elastic lidar. Los Alamos National Laboratory Report (to appear)

4. Tunnell, T. W. and Clark, D. A.: Characterization of debris cloud from $1 \mathrm{~kg}$ of high explosives. Los Alamos National Laboratory Report (to appear)

5. Buttler, W. T.: Three-dimensional winds: A maximum cross-correlation application to elastic lidar data. Los Alamos National Laboratory Report LA-13121-T. (1996)

This article was processed using the IATEX macro package with LLNCS style 